\title{
Validation of the PTSD Checklist for DSM-5 (PCL-5) on Patients Injured in Car Accidents
}

\author{
Zack Z. Cernovsky, Milad Fattahi, Larry C. Litman, and David M. Diamond
}

\section{ABSTRACT}

Background: The PTSD Checklist for DSM-5 (PCL-5), is presently the most widely used psychological measure of PTSD along the criteria of DSM-5. We examined the criterion validity of PCL-5 separately for each of its 20 items by comparing scores of patients injured in high impact motor vehicle accidents (MVAs) to scores of persons in a control group. In addition, we evaluated criterion and convergent validity of the PCL-5 total scores.

Method: De-identified data of 80 post-MVA patients (mean age 38.9 years, $\mathrm{SD}=12.8$ ) included their scores on the PCL-5, Brief Pain Inventory (BPI), Insomnia Severity Index (ISI), Rivermead Post-concussion Symptoms Questionnaire, Subjective Neuropsychological Symptoms Scale (SNPSS), ratings of depression, anger, and anxiety (Items 10 to 12 of the Whiplash Disability Questionnaire), and three questionnaire measures of driving anxiety (Steiner's, Whetstone's, and DAQ). The patients were assessed, on the average, 49.7 weeks $(\mathrm{SD}=36.3)$ after their MVA, but all still experienced active post-MVA symptoms requiring therapy.

The PCL-5 scores were also available from 21 controls (mean age 43.0 years, $\mathrm{SD}=20.3$ ).

Results and Discussion: With respect to criterion validity of the PCL-5, the post-MVA patients differed significantly from the control group not only with respect to their total PCL-5 scores, but also on all 20 individual items of the PCL-5, and also on all 4 subscales of PCL-5 (Intrusion, Avoidance, Altered Cognitions/Mood, and Arousal). The PCL-5 total scores correlated significantly to all three measures of post-MVA driving anxiety, post-MVA pain and insomnia, post-MVA depression, anger, and generalized anxiety, and to post-MVA subjective neuropsychological symptoms in the postconcussion and whiplash spectrum.

Conclusions: Both the criterion and convergent validity of the PCL-5 for the use on post-MVA patients are excellent.

Keywords: PTSD, PCL-5, criterion validity, convergent validity, motor vehicle accidents.

\section{INTRODUCTION}

The PTSD Checklist for DSM-5 (PCL-5) [1] is the most widely used psychological questionnaire measure of PTSD, both for routine clinical work and for research purposes. It has been translated into numerous languages. The PCL-5 closely represents the DSM-5 diagnostic criteria for PTSD.

The PCL-5 is a 20-item questionnaire. Each item is scored via scale from $0=$ not at all, $1=\mathrm{a}$ little bit, $2=$ moderately, $3=$ quite a bit, and 4=extremely.

There have been numerous validations of its previous versions, those designed for previous version of DSM, and there are also many validations of its current version, i.e., the PCL-5, in English and other languages [2], [3]. The validations were mostly undertaken on US veterans, but some were on other clinical groups: HIV positive patients, addicted patients, recipients of bone marrow transplant, women with
Submitted : March 29, 2021

Published : April 19, 2021

ISSN: 2593-8339

DOI: $10.24018 /$ ejmed.2021.3.2.790

\section{Z. Z. Cernovsky*}

Department of Psychiatry, Western University, Ontario, Canada.

(e-mail: drcernovsky@gmail.com)

M. Fattahi

(M. Psy. student) Adler Graduate

Professional School, Toronto,

Ontario, Canada.

L. C. Litman

Department of Psychiatry, Western University, Ontario, Canada.

(e-mail: corvette033@ ${ }^{@}$ hotmail.com) D.M. Diamond

Department of Psychology, University of South Florida, USA.

(e-mail: ddiamond@ usf.edu)

*Corresponding Author breast cancer, mothers of pediatric cancer survivors [2]. Noteworthy are validations of the Chinese version of PCL-5 on frontline healthcare workers in the outbreak of COVID-19 by Cheng et al. [4], and of the Portuguese version on firefighters by Carvalho et al. [5], and of the German version on a heterogenous sample of persons who experienced trauma in the form of physical assaults, or traffic accidents, other accidents, sexual assaults, combat, or natural disasters [6].

Psychometric properties of PCL-5 have been found satisfactory in a US study by Bovin et al. [7] on veterans: the cutoff scores recommended in their study were 31,32 , or 33 . All these 3 cutoffs were diagnostically efficient.

Another US study of psychometric properties of PCL-5 was carried out by Blevin et al. [8] on a sample of college students who reported exposure to a trauma: traffic accidents were reported by $25.5 \%$, physical or sexual assault by $22.8 \%$, sudden violent or accidental death of a loved one by $14.4 \%$, 
life-threatening illness or injury by $13.7 \%$, and fire or natural disaster by $10.1 \%$.

One of the frequent medical conditions associated with PTSD is chronic pain [9], [10]. The meta-analytic review by Siqveland's team [10] of PTSD's comorbidity with chronic pain showed that the pooled PTSD prevalence in various studies of persons with pain was $9.7 \%$. The lowest prevalence was in a population based study of persons with lower back pain (none of them had PTSD) and the highest was in patients with fibromyalgia ( $57 \%$ of the participants had PTSD). A systematic review of studies on chronic pain's association with PTSD by Fishbain's team [9] estimated PTSD prevalence in the general population of persons with chronic pain at $9.8 \%$. The frequencies of PTSD ranged from $0.69 \%$ for chronic low back pain to $50.1 \%$ in veterans.

The standards for psychological testing stipulated by the American Psychological Association (APA) require that a test should be validated separately on each clinical group on which a routine use is intended [11]. The PCL-5 is used routinely on persons injured in motor vehicle accidents (MVAs). Although some of the validation studies of PCL-5 included mixed samples of persons with various type of trauma, including also some persons who experienced an MVA [6], [8], a separate validation study of PCL-5 on a homogeneous sample consisting only of post-MVA patients is much needed. Similarly, to veterans, the PTSD in survivors of MVAs may be comorbid with chronic pain.

The present study examines the criterion validity of each of 20 items of the PCL-5 by comparing scores of patients injured in motor vehicle accidents (MVAs) to scores of a control group. This validation procedure was also applied to PCL-5 total scores and to scores on its four subscales. In addition, the convergent validity of PCL-5 is assessed via its correlations with clinical variables including pain, insomnia, post-MVA depression and anxiety, and symptoms within the post-concussion and whiplash spectrum.

\section{METHOD}

De-identified data sets were available on 80 persons injured in motor vehicle accidents (MVAs) and 21 persons in a control group.

The sample of the post-MVA patients consisted of 34 men and 46 women (mean age $=38.9$ years, $\mathrm{SD}=12.8$; range 15 to 65). All patients in this sample could be classified as experiencing some degree of the post-concussion syndrome (scores ranging from 28 to 60 on the Rivermead scale [12], [13], with mean=45.5, $\mathrm{SD}=8.5$ ).

Their average scores were $19.9(\mathrm{SD}=12.9)$ on the Subjective Neuropsychological Symptoms Scale (SNPSS) [14], 6.2 ( $\mathrm{SD}=1.7)$ on the "average pain" item of the Brief Pain Inventory [15], and 23.1 (SD=4.8) on Morin's Insomnia Severity Index [16]. The time elapsed since the patient's MVA ranged from 8 to 194 weeks, with the average at 49.7 weeks $(\mathrm{SD}=36.3)$, i.e., about a year. They all still experienced active post-accident symptoms that required therapy.

Available were also the patients' ratings on Items 10 to 12 of the Whiplash Disability Questionnaire [17], that is, ratings of depression, anger, and of anxiety via scales from 0 ("not at all") to 10 ("always").
In this sample, 61 had no previous MVA, 15 had one MVA, and 3 patients had 2 or more MVAs. In their recent vehicular accident, 61 were the drivers, 15 were passengers, and 4 were pedestrians.

The information about the loss of consciousness in the MVA was available for 77 of the 80 patients: 30 believed they did not lose consciousness, 30 were uncertain, 15 reported a brief loss of consciousness, and 3 lost consciousness for longer than 5 minutes. Their scores on the Immediate Concussion Symptoms (ICS) scale [18] ranged from 1 to 7 points (mean=5.2, $\mathrm{SD}=1.6)$.

Most of the patients developed driving anxiety after their MVA and required related psychological treatment. Their scores ranged from 23 to 93 (mean=63.8, $\mathrm{SD}=19.0$ ) on the Whetstone Vehicle Anxiety Questionnaire [19], from 41 to 123 (mean=91.6, $\mathrm{SD}=25.1$ ) on the Driving Anxiety Questionnaire (DAQ)[19], and from 10.5 to 18 (mean=14.9, $\mathrm{SD}=2.1$ ) on Steiner's Automobile Anxiety Inventory [20].

The sample of the controls (11 men, 10 women) included only persons who did not experience a situation of narrowly avoiding death, serious injury, or sexual violence, and did not directly witness such a traumatic event, and were not informed that such an event happened to their close friend or relative. Their age ranged from 23 to 79 years, with the mean of 43.0 years $(\mathrm{SD}=20.3)$.

\section{RESULTS}

\section{A. Total Scores on the PCL-5}

It is noteworthy that there was no overlap in PCL-5 scores between our controls (their scores ranged from 0 to 8 points, mean=1.1, SD=2.2) and the post-MVA patients (their scores ranged from 16 to 80 points, mean=55.4, $\mathrm{SD}=13.8$ ). The magnitude of the difference in mean PCL-5 total scores corresponds to a correlation coefficient of $\mathrm{r}=.87$.

The lowest item-total correlations (i.e., the item correlation to the total score calculated without including that particular item) were .40 for Item 16 (taking too many risks) and .55 for Item 8 (trouble remembering the details of stressful event). All other item-total correlations were $>.71$.

The Cronbach Alpha coefficient of internal consistency calculated for the PCL-5 scale was .98 and did not markedly change if items 16 or 8 were deleted. In fact, the deletion of any of the 20 individual items always resulted in a Cronbach Alpha in the range of .97 to .98 , i.e., in no noteworthy change or improvement of internal consistency of PCL-5.

\section{B. Individual Items of the PCL-5}

In the PCL-5 scoring system, as already explained, the responses to each of the 20 items are "not at all" $=0$, "a little bit" $=1$, "moderately" $=2$, "quite a bit" $=3$, and "extremely" $=4$. The mean values of the controls were significantly lower on all 20 PCL-5 items than those of MVA patients, see Table I.

The last column of the Table 1 lists correlation coefficients corresponding to the differences in mean raw scores on the 20 PCL-5 items between the post-MVA patients and controls

\section{PCL-5 Subscales}

In the diagnostic use of PCL-5, the first 5 items as a group assess the degree of intrusive mentation, the next 2 items (Items 6 and 7) assess avoidance, Items 8 to 14 assess altered 
cognitions/mood, and Items 15 to 20 assess the degree of arousal.

The scores on these 4 subscales (labelled here as Intrusion, Avoidance, Altered Cognitions/Mood, and Arousal) of the post-MVA patients and of the controls are reported in Table II. Scores on all 4 subscales were significantly higher in postMVA patients than in the controls.

TABLE I: MEANS AND SDs OF MVA PATIENTS VERSUS CONTROLS ON PCL-5 ITEMS

\begin{tabular}{|c|c|c|c|}
\hline \multirow[b]{2}{*}{ PCL-5 Items: } & \multicolumn{2}{|c|}{ Mean scores: } & \multirow{2}{*}{$\begin{array}{l}\text { Correlation } \\
\text { Coefficient }\end{array}$} \\
\hline & $\begin{array}{c}\text { MVA } \\
\text { Patients }\end{array}$ & Controls & \\
\hline $\begin{array}{l}\text { 1. Repeated, disturbing, and unwanted } \\
\text { memories of the stressful experience? }\end{array}$ & $3.0(1.0)$ & $0.1(0.4)$ & .78 \\
\hline $\begin{array}{l}\text { 2. Repeated, disturbing dreams of the } \\
\text { stressful experience? }\end{array}$ & $2.2(1.6)$ & $0.0(0.2)$ & .52 \\
\hline $\begin{array}{l}\text { 3. Suddenly feeling or acting as if the } \\
\text { stressful experience were actually } \\
\text { happening again (as if you were } \\
\text { actually back there reliving it)? }\end{array}$ & $2.6(1.2)$ & $0.0(0.0)$ & .71 \\
\hline $\begin{array}{l}\text { 4. Feeling very upset when something } \\
\text { reminded you of the stressful } \\
\text { experience? }\end{array}$ & $3.2(0.9)$ & $0.1(0.3)$ & .84 \\
\hline $\begin{array}{l}\text { 5. Having strong physical reactions } \\
\text { when something reminded you of the } \\
\text { stressful experience (for example, } \\
\text { heart pounding, trouble breathing, } \\
\text { sweating)? }\end{array}$ & $3.1(1.1)$ & $0.0(0.0)$ & .78 \\
\hline $\begin{array}{l}\text { 6. Avoiding memories, thoughts, or } \\
\text { feelings related to the stressful } \\
\text { experience? }\end{array}$ & $2.9(1.1)$ & $0.0(0.2)$ & .77 \\
\hline $\begin{array}{l}\text { 7. Avoiding external reminders of the } \\
\text { stressful experience (for example, } \\
\text { people, places, conversations, } \\
\text { activities, objects, or situations)? }\end{array}$ & $2.9(1.0)$ & $0.0(0.2)$ & .79 \\
\hline $\begin{array}{l}\text { 8. Trouble remembering important } \\
\text { parts of the stressful experience? }\end{array}$ & $1.7(1.6)$ & $0.1(0.4)$ & .43 \\
\hline $\begin{array}{l}\text { 9. Having strong negative beliefs about } \\
\text { yourself, other people, or the world } \\
\text { (for example, having thoughts such as: } \\
\text { I am bad, there is something seriously } \\
\text { wrong with me, no one can be trusted, } \\
\text { the world is completely dangerous)? }\end{array}$ & $2.6(1.4)$ & $0.1(0.3)$ & .61 \\
\hline $\begin{array}{l}\text { 10. Blaming yourself or someone else } \\
\text { for the stressful experience or what } \\
\text { happened after it? }\end{array}$ & $2.9(1.3)$ & $0.1(0.3)$ & .71 \\
\hline $\begin{array}{l}\text { 11. Having strong negative feelings } \\
\text { such as fear, horror, anger, guilt, or } \\
\text { shame? }\end{array}$ & $3.1(0.9)$ & $0.0(0.2)$ & .84 \\
\hline $\begin{array}{l}\text { 12. Loss of interest in activities that } \\
\text { you used to enjoy? }\end{array}$ & $3.4(0.9)$ & $0.0(0.2)$ & .86 \\
\hline $\begin{array}{l}\text { 13. Feeling distant or cut off from other } \\
\text { people? }\end{array}$ & $3.0(1.2)$ & $0.0(0.2)$ & .74 \\
\hline $\begin{array}{l}\text { 14. Trouble experiencing positive } \\
\text { feelings (for example, being unable to } \\
\text { feel happiness or have loving feelings } \\
\text { for people close to you)? }\end{array}$ & $2.7(1.2)$ & $0.0(0.0)$ & .70 \\
\hline $\begin{array}{l}\text { 15. Irritable behavior, angry outbursts, } \\
\text { or acting aggressively? }\end{array}$ & $2.9(1.2)$ & $0.0(0.2)$ & .71 \\
\hline $\begin{array}{l}\text { 16. Taking too many risks or doing } \\
\text { things that could cause you harm? }\end{array}$ & $0.9(1.3)$ & $0.0(0.2)$ & .28 \\
\hline $\begin{array}{l}\text { 17. Being super alert or watchful or on } \\
\text { guard? }\end{array}$ & $3.4(0.8)$ & $0.0(0.2)$ & .88 \\
\hline 18. Feeling jumpy or easily startled? & $3.0(1.0)$ & $0.0(0.0)$ & .80 \\
\hline 19. Having difficulty concentrating? & $3.1(1.0)$ & $0.0(0.2)$ & .81 \\
\hline 20. Trouble falling or staying asleep? & $3.5(0.8)$ & $0.1(0.5)$ & .87 \\
\hline Total score - PCL-5 & $\begin{array}{c}55.4 \\
(13.8) \\
\end{array}$ & $1.1(2.2)$ & .87 \\
\hline
\end{tabular}

Legend: All correlations are significant at $p<.001,2$-tailed, except for Item 16 on which the between-groups difference is significant at $\mathrm{p}=.005,2$-tailed.
TABLE II: MEANS AND SDs OF MVA PATIENTS VERSUS CONTROLS ON PCL-5 SUBSCALES

\begin{tabular}{cccc}
\hline \multirow{2}{*}{ PCL-5 subscales: } & \multicolumn{2}{c}{ Mean scores: } & \multirow{2}{*}{$\begin{array}{c}\text { Correlation } \\
\text { Coefficient }\end{array}$} \\
\cline { 2 - 3 } & $\begin{array}{c}\text { MVA } \\
\text { Patients }\end{array}$ & Controls & \\
\hline Intrusion (Items 1-5) & $14.1(4.8)$ & $0.3(0.7)$ & .80 \\
Avoidance (Items 6-7) & $5.8(1.8)$ & $0.1(0.4)$ & .82 \\
Altered Cognitions/Mood & $19.3(5.3)$ & $0.4(1.1)$ & .85 \\
(Items 8-14) & $16.8(3.9)$ & $0.3(0.8)$ & .89 \\
Arousal (Items 15-20) & & \\
\hline
\end{tabular}

Legend: All correlations are significant at $\mathrm{p}<.001,2$-tailed.

All these 4 subscales are highly intercorrelated (Pearson rs $>85$ ) and they all correlated highly with the total PCL-5 scores (Pearson rs > 91), see Table III.

TABLE III: INTERCORRELATIONS OF THE 4 SUBSCALES (PEARSON rs)

\begin{tabular}{lcccc}
\hline & Intrusion & Avoidance & $\begin{array}{c}\text { Altered } \\
\text { Cognitions } \\
\text { /Mood }\end{array}$ & Arousal \\
\hline $\begin{array}{c}\text { Total PCL- } \\
5 \text { score }\end{array}$ & .95 & .92 & .96 & .96 \\
$\begin{array}{c}\text { Intrusion } \\
\text { Avoidance }\end{array}$ & .89 & .89 & .88 & .89 \\
$\begin{array}{c}\text { Altered } \\
\text { Cognitions/ } \\
\begin{array}{c}\text { Mood } \\
\text { Arousal }\end{array}\end{array}$ & .88 & .86 & .86 & .87 \\
\hline Legend: All correlations are significant at $\mathrm{p}<.001,2$-tailed. &
\end{tabular}

\section{Endorsed PTSD Symptoms}

If the score on an item is 2 or higher, then the symptom represented by that particular item is considered as "endorsed" by the patient [8] i.e., as indicating the clinically meaningful presence of the given symptom. The proportions of MVA patients and of controls endorsing each PCL-5 item are summarized in Table IV.

For the diagnosis of PTSD consistent with DSM-5, there must be at least one "endorsed" item in the subscale "Intrusion" (Items 1 to 5), at least one item in the subscale of "Avoidance," at least 2 items in the subscale "Altered Cognitions/Mood," and at least 2 items in the subscale of "Arousal." In addition, the patient also must meet the cutoff for the total PCL-5 score. As mentioned, tentative diagnostic cutoffs of 31,32 , or 33 points for the total score have been suggested for total PCL-5 scores (see Bovin et al. [7]). In the present study, the cutoff was set to $>32$ points.

In our sample of post-MVA patients, total PCL-5 scores ranged from 16 to 80 points. All but 4 of the patients scored above the cutoff of 32 points. Among these 4 cases of subclinical PTSD, only one patient met the diagnostic requirements of at least one endorsed item for subscale "Intrusion," one for "Avoidance," two for "Altered Cognitions/Mood," and two for "Arousal."

The total PCL-5 scores of persons in the control group ranged from 0 to 8 points, i.e., none reached the cutoff score. Furthermore, none of the controls met the diagnostic requirements of minimum number of endorsed items on each of the 4 subscales.

It is clear from these various statistics that the total PCL-5 score and its 20 individual items have very satisfactory criterion validity. 
TABLE IV: PROPORTIONS OF MVA PATIENTS VERSUS CONTROLS ENDORSING ITEM AT 2 POINTS OR HIGHER

\begin{tabular}{|c|c|c|}
\hline PCL-5 Items: & $\begin{array}{c}\text { MVA } \\
\text { Patients }\end{array}$ & Controls \\
\hline $\begin{array}{l}\text { 1. Repeated, disturbing, and unwanted } \\
\text { memories of the stressful experience? }\end{array}$ & $88.8 \%$ & $0.0 \%$ \\
\hline $\begin{array}{l}\text { 2. Repeated, disturbing dreams of the } \\
\text { stressful experience? }\end{array}$ & $62.5 \%$ & $0.0 \%$ \\
\hline $\begin{array}{l}\text { 3. Suddenly feeling or acting as if the } \\
\text { stressful experience were actually happening } \\
\text { again (as if you were actually back there } \\
\text { reliving it)? }\end{array}$ & $85.0 \%$ & $0.0 \%$ \\
\hline $\begin{array}{l}\text { 4. Feeling very upset when something } \\
\text { reminded you of the stressful experience? }\end{array}$ & $95.0 \%$ & $0.0 \%$ \\
\hline $\begin{array}{l}\text { 5. Having strong physical reactions when } \\
\text { something reminded you of the stressful } \\
\text { experience (for example, heart pounding, } \\
\text { trouble breathing, sweating)? }\end{array}$ & $88.8 \%$ & $0.0 \%$ \\
\hline $\begin{array}{l}\text { 6. Avoiding memories, thoughts, or feelings } \\
\text { related to the stressful experience? }\end{array}$ & $87.5 \%$ & $0.0 \%$ \\
\hline $\begin{array}{l}\text { 7. Avoiding external reminders of the } \\
\text { stressful experience (for example, people, } \\
\text { places, conversations, activities, objects, or } \\
\text { situations)? }\end{array}$ & $93.8 \%$ & $0.0 \%$ \\
\hline $\begin{array}{l}\text { 8. Trouble remembering important parts of } \\
\text { the stressful experience? }\end{array}$ & $53.8 \%$ & $4.8 \%$ \\
\hline $\begin{array}{l}\text { 9. Having strong negative beliefs about } \\
\text { yourself, other people, or the world (for } \\
\text { example, having thoughts such as: I am bad, } \\
\text { there is something seriously wrong with me, } \\
\text { no one can be trusted, the world is } \\
\text { completely dangerous)? }\end{array}$ & $77.5 \%$ & $0.0 \%$ \\
\hline $\begin{array}{l}\text { 10. Blaming yourself or someone else for the } \\
\text { stressful experience or what happened after } \\
\text { it? }\end{array}$ & $83.8 \%$ & $0.0 \%$ \\
\hline $\begin{array}{l}\text { 11. Having strong negative feelings such as } \\
\text { fear, horror, anger, guilt, or shame? }\end{array}$ & $92.5 \%$ & $0.0 \%$ \\
\hline $\begin{array}{l}\text { 12. Loss of interest in activities that you used } \\
\text { to enjoy? }\end{array}$ & $95.0 \%$ & $0.0 \%$ \\
\hline $\begin{array}{l}\text { 13. Feeling distant or cut off from other } \\
\text { people? }\end{array}$ & $88.8 \%$ & $0.0 \%$ \\
\hline $\begin{array}{l}\text { 14. Trouble experiencing positive feelings } \\
\text { (for example, being unable to feel happiness } \\
\text { or have loving feelings for people close to } \\
\text { you)? }\end{array}$ & $83.8 \%$ & $0.0 \%$ \\
\hline $\begin{array}{l}\text { 15. Irritable behavior, angry outbursts, or } \\
\text { acting aggressively? }\end{array}$ & $85.0 \%$ & $0.0 \%$ \\
\hline $\begin{array}{l}\text { 16. Taking too many risks or doing things } \\
\text { that could cause you harm? }\end{array}$ & $26.2 \%$ & $0.0 \%$ \\
\hline $\begin{array}{l}\text { 17. Being super alert or watchful or on } \\
\text { guard? }\end{array}$ & $97.5 \%$ & $0.0 \%$ \\
\hline 18. Feeling jumpy or easily startled? & $87.5 \%$ & $0.0 \%$ \\
\hline 19. Having difficulty concentrating? & $95.0 \%$ & $0.0 \%$ \\
\hline 20. Trouble falling or staying asleep? & $96.2 \%$ & $4.8 \%$ \\
\hline
\end{tabular}

\section{E. Convergent Validity of the PCL-5}

Convergent validity is the extent to which the scale correlates with variables to which it is theoretically expected to be related. Briefly, the PCL-5 should correlate positively with scales measuring related constructs such as the postMVA driving anxiety, or with psychological variables that make a recovery from PTSD more difficult, such as persistent pain, depression, various symptoms of insomnia, and subjective symptoms within the post-concussion and whiplash spectrum.

As shown in Table V, the convergent validity of the PCL5 appears satisfactory, as indicated by its significant correlations to measures of driving anxiety, insomnia, pain, depression, anger, generalized anxiety, and to subjective neuropsychological variables from the post-concussion and whiplash spectrum.
TABLE V: CORRELATIONS OF THE PCL-5 TO ClinICAL VARIABLES (DATA OF POST-MVA PATIENTS ONLY)

\begin{tabular}{lcc}
\hline & $\begin{array}{c}\text { Pearson } \\
\text { Correlations }\end{array}$ & $\begin{array}{c}\text { P values } \\
\text { (2-tailed) }\end{array}$ \\
\hline $\begin{array}{l}\text { Whetstone Vehicle Anxiety } \\
\text { Questionnaire [19], N=36 }\end{array}$ & .79 & $\mathrm{p}<.001$ \\
$\begin{array}{l}\text { Driving Anxiety Questionnaire [19], } \\
\mathrm{N}=41\end{array}$ & .67 & $\mathrm{p}<.001$ \\
Steiner's Automobile Anxiety Inventory & & \\
[20], N=31 & .31 & $\mathrm{p}=.050$ \\
Ratings on Items 3 to 5 of the Brief Pain & & \\
Inventory [15], N=80: & & \\
Worst pain & .42 & $\mathrm{p}<.001$ \\
Least pain & .41 & $\mathrm{p}<.001$ \\
Average pain & .45 & $\mathrm{p}<.001$ \\
Insomnia Severity Index [16], N=80 & .68 & $\mathrm{p}<.001$ \\
Rivermead Post-Concussion Symptoms & .63 & $\mathrm{p}<.001$ \\
Questionnaire [12], N=60 & & \\
Subjective Neuropsychological & .57 & $\mathrm{p}<.001$ \\
Symptoms scale (SNPSS) [14], N=44 & & \\
Immediate Concussion Symptoms scale & .33 & $\mathrm{p}=.037$ \\
[18], N=41 & & \\
Ratings on Items 10 to 12 on the & & \\
Whiplash Disability Questionnaire [17], & & $\mathrm{p}<.001$ \\
N=53 & & \\
Depression & & \\
Anger & & \\
Generalized Anxiety & & \\
\hline
\end{tabular}

Since the Item 20 of PCL-5 measures sleep difficulties, we have also separately calculated the correlation of the Insomnia Severity Index to a revised total PCL-5 score from which the Item 20 was deducted, to avoid an undue inflation of the correlation coefficient. The resulting Pearson correlation was only slightly lower and still significant $(\mathrm{r}=.65$, $\mathrm{p}<.001,2$-tailed).

In this context, it is also noteworthy that the PCL-5 scores have not correlated significantly with age $(\mathrm{r}=-.13)$ and gender $(\mathrm{r}=.04)$. No significant correlations of PCL-5 scores were found to the number of previous MVAs associated with injuries $(\mathrm{r}=.11)$ and to number of weeks elapsed since the patient's MVA $(\mathrm{r}=.03)$ : all patients still experienced active post-MVA symptoms requiring therapy.

\section{DISCUSSION}

According to Ursano, serious car accidents are perhaps the most common cause of PTSD [21]. For this reason, a validation of clinical measures of PTSD on injured motorists, especially of the already widely used PCL-5, is methodologically important.

With respect to criterion validity of the PCL-5, the postMVA patients differed significantly from persons in the control group not only with respect to their total PCL-5 scores, but also on all 20 individual items of the PCL-5, and also on all 4 diagnostically important clusters of PCL-5 (Intrusion, Avoidance, Altered Cognitions/Mood, and Arousal).

With respect to convergent validity of the PCL-5, significant correlations were found of the PCL-5 total scores to measures of post-MVA driving anxiety, post-MVA pain and insomnia, post-MVA depression, anger, and generalized anxiety, and to post-MVA subjective neuropsychological symptoms in the post-concussion and whiplash spectrum, and to retrospective ratings on the Immediate Concussion Symptoms scale. 
As mentioned, the test development standards stipulated by the American Psychological Association recommend that each test should be separately validated for each clinical group for which it is to be used routinely.[11] The data from our study document that PCL-5 shows an excellent criterion validity and convergent validity when used on patients injured in high impact MVAs.

As formulated in Diamond and Zoladz's neuropsychological review, page 441 [22] "amygdalamediated heightened vigilance in PTSD maximizes the likelihood that a traumatized person will not be caught off guard by a predator; however, the loss of sleep, intrusive memories, traumatic nightmares, impaired cognition, and increased susceptibility to a multitude of diseases are devastating to quality of life. The misery caused by a hyperfunctional amygdala in PTSD is the cost of inheriting an evolutionarily primitive mechanism that considers survival more important than the quality of one's life." [22]

Chronic PTSD can predispose the person to other medical problems, including those of somatic nature. The "amygdala is intimately connected with cortical and subcortical structures that allow it to be sensitive to sensory cues as well as to cognitive features of fear to activate the fight, flight, or freeze (FFF) response [23]. The FFF response is evolutionarily adapted to optimize survival in advance of or in response to an attack" (in Diamond and Zoladz, page 440 [22]).

In PTSD, "the repeated unbidden activation of intrusive memories and the FFF response underlies brain and somatic pathology, including amygdala hypertrophy and impaired hippocampal and prefrontal cortex functioning ..... as well as an increased incidence of cardiovascular, metabolic, and immunological disorders ......" (in Diamond and Zoladz, page 441 [22]).

Williamson's team [24] suggested that chronic PTSD is associated with maladaptive autonomic regulation which may lead to related cardiovascular, metabolic, and inflammatory systemic changes which affect the body in a manner consistent with accelerated aging. Preliminary findings in this area by the investigations of the team of VA scientists led by Erika Wolf on 346 US veterans (mean age 32.48 years, $\mathrm{SD}=8.95)$ "provide evidence that PTSD confers risk for cardiometabolic pathology and neurodegeneration and raise concern that this cohort may be aging prematurely and at risk for substantial medical and cognitive decline" [25]. This research highlights the importance of diagnosing and treating PTSD.

\section{CONCLUSIONS}

The data from our study document that PCL-5 shows an excellent criterion validity and convergent validity when used on patients injured in high impact MVAs.

\section{REFERENCES}

[1] Weathers FW, Litz BT, Keane TM, Palmieri PA, Marx BP, \& Schnurr PP. The PTSD Checklist for DSM-5 (PCL-5). The National Center for PTSD, US Department of Veterans Affairs, Washington, DC, 2013. www.ptsd.va.gov.
[2] McDonald SD, \& Calhoun PS. The diagnostic accuracy of the PTSD Checklist: A critical review. Clinical Psychology Review. 2010; 30:976-987. doi:10.1016/j.cpr.2010.06.012.

[3] Wilkins KC, Lang AJ, \& Norman SB. Synthesis of the psychometric properties of the PTSD Checklist (PCL) Military, Civilian, and Specific versions. Depression and Anxiety. 2011; 28:596-606. doi:10.1002/da.20837.

[4] Cheng P, Xu LZ, Zheng WH, Ng RMK, Zhang L, Li LJ, Li WH Psychometric property study of the posttraumatic stress disorder checklist for DSM-5 (PCL-5) in Chinese healthcare workers during the outbreak of corona virus disease 2019. Journal of Affective Disorders. 2020 Dec 1; 277:368-374. doi: 10.1016/j.jad.2020.08.038

[5] Carvalho T, da Motta C, Pinto-Gouveia J. Portuguese version of the Posttraumatic Stress Disorder Checklist for DSM-5 (PCL-5): Comparison of latent models and other psychometric analyses. Journal of Clinical Psychology. 2020;76(7):1267-1282. doi: 10.1002/jclp.22930.

[6] Krüger-Gottschalk A, Knaevelsrud C, Rau H, Dyer A, Schäfer I, Schellong J, Ehring T. The German version of the Posttraumatic Stress Disorder Checklist for DSM-5 (PCL-5): psychometric properties and diagnostic utility. BMC Psychiatry. 2017 Nov 28;17(1):379. doi: 10.1186/s12888-017-1541-6.

[7] Bovin MJ, Marx BP, Weathers FW, Gallagher MW, Rodriguez P, Schnurr PP, Keane TM. Psychometric properties of the PTSD checklist for diagnostic and statistical manual of mental disorders - fifth edition (PCL-5) in veterans. Psychological Assessment. 2016; 28:1379-91.

[8] Blevins CA, Weathers FW, Davis MT, Witte TK, and Domino JL. The Posttraumatic Stress Disorder Checklist for DSM-5 (PCL-5): Development and Initial Psychometric Evaluation. Journal of Traumatic Stress. 2015; 28:489-498. doi: 10.1002/jts.22059.

[9] Fishbain DA, Pulikal A, Lewis JE, Gao J. Chronic Pain Types Differ in Their Reported Prevalence of Post -Traumatic Stress Disorder (PTSD) and There Is Consistent Evidence That Chronic Pain Is Associated with PTSD: An Evidence-Based Structured Systematic Review. Pain Medicine. 2017;18(4):711-735. doi:10.1093/pm/pnw065

[10] Siqveland J, Hussain A, Lindstrøm JC, Ruud T, Hauff E. Prevalence of Posttraumatic Stress Disorder in Persons with Chronic Pain: A Metaanalysis. Frontiers in Psychiatry. 2017;14(8): article 164, p. 1-9. doi: 10.3389/fpsyt.2017.00164.

[11] American Educational Research Association, American Psychological Association, National Council on Measurement in Education. The Standards for Educational and Psychological Testing. Washington, DC.: AERA Publications, 2014.

[12] King NS, Crawford S, Wenden FJ, Moss NEG, Wade DT. The Rivermead Post Concussion Symptoms Questionnaire: a measure of symptoms commonly experienced after head injury and its reliability. Journal of Neurology. 1995; 242:587-592.

[13] Cernovsky ZZ, Mann SC, Velamoor V, Oyewumi LK, Diamond DM, Litman LC. Validation of the Rivermead Post-Concussion Symptoms Questionnaire (RPQ) on Patients Injured in High Impact Car Accidents. Archives of Psychiatry and Behavioral Sciences. 2021;4(1):14-22. doi.org/10.22259/2638-5201.0401003.

[14] Cernovsky ZZ, Litman LC, Mann SC, Oyewumi LK, Bureau Y, Mendonça JD, Diamond DM, and Raheb H. Validation of the Subjective Neuropsychological Symptoms Scale (SNPSS) in Injured Motorists. Archives of Psychiatry and Behavioral Sciences. 2021;4(1):6-13.

[15] Cleeland CS. The Brief Pain Inventory - User Guide. Houston, TX: The University of Texas - M. D. Anderson Cancer Center, 2009.

[16] Morin CM, Belleville G, Bélanger L, and Ivers H. The insomnia severity index: psychometric indicators to detect insomnia cases and evaluate treatment response. Sleep. 2011; 34:601-608.

[17] Pinfold M, Niere KR, O'Leary EF, Hoving JL, Green S and Buchbinder R. Validity and internal consistency of a Whiplash-Specific disability measure. Spine. 2004;29(3):263-268.

[18] Cernovsky Z, Istasy P, Bureau Y, Chiu S. Scale for retrospective assessment of immediate concussion symptoms. Mental Illness. 2018;10(2):70-71 and Appendix (2 pages). https://doi.org/10.4081/mi.2018.7901.

[19] Whetstone JP, Cernovsky Z, Tenenbaum S, Poggi G, Sidhu A, Istasy M, Dreer M. Validation of James Whetstone's Measure of Amaxophobia. Archives of Psychiatry and Behavioral Sciences. 2020;3(1):23-33.

[20] Cernovsky ZZ, Fattahi M, Litman LC, Tenenbaum S, Leung B, Nosonova V, Zhao C, and Dreer M. Validity of Steiner's Automobile Anxiety Inventory. European Journal of Medical and Health Sciences. 2021;3(1):56-61 doi: 10.24018/ejmed.2021.3.1.661

[21] Ursano RJ, Fullerton CS, Epstein RS, Crowley B, Kao T-C, Vance K, Craig KJ, Dougall AL, Baum A. Acute and chronic posttraumatic stress 
disorder in motor vehicle accident victims. American Journal of Psychiatry. 1999;156(4):589-95. doi: 10.1176/ajp.156.4.589.

[22] Diamond DM and Zoladz PR. Dysfunctional or Hyperfunctional? The Amygdala in Posttraumatic Stress Disorder Is the Bull in the Evolutionary China Shop. Journal of Neuroscience Research. 2016; 94:437-444. doi: 10.1002/jnr.23684.

Mobbs D, Hagan CC, Dalgleish T, Silston B, Prevost C. 2015. The ecology of human fear: survival optimization and the nervous system. Frontiers in Neuroscience. 2015; 9:55. doi: 10.3389/fnins.2015.00055.

[23] Williamson JB, Porges EC, Lamb DG, Porges SW. Maladaptive autonomic regulation in PTSD accelerates physiological aging. Frontiers of Psychology. 2015; 5:1571.

[24] Wolf EJ, Sadeh N, Leritz EC, Logue MW, Stoop TB, McGlinchey R, Milberg W, Miller NW. Posttraumatic Stress Disorder as a Catalyst for the Association Between Metabolic Syndrome and Reduced Cortical Thickness. Biological Psychiatry. 2016;80(5):363-71. doi: 10.1016/j.biopsych.2015.11.023.

Zack Z. Cernovsky is the professor of psychiatry in the medical school of Western University, London, Ontario, Canada. Dr. Cernovsky has published close to 200 scientific articles in the field of psychiatry and medical psychology, and also chapters in university textbooks.

Milad Fattahi is completing master's degree requirements in psychology at Adler Graduate Professional School, Toronto, Ontario, Canada. He has coauthored various publications on psychological symptoms of injured motorists.

Larry Craig Litman obtained his Ph.D. in clinical psychology from York University, Ontario, Canada. He has taught classes in statistics at that university. Dr. Litman is currently on faculty staff of the Department of Psychiatry, Schulich school of Medicine \& Dentistry, Western University, London, Ontario, Canada. He has published numerous empirical studies in clinical psychology and psychiatry.

David M. Diamond received his Ph.D. in Neuroscience from the University of California, Irvine. He is a professor in the Department of Psychology at the University of South Florida and recently retired from the Department of Veterans Affairs as a Career Scientist. Professor Diamond has published over 100 papers on the brain, stress, memory and PTSD. 